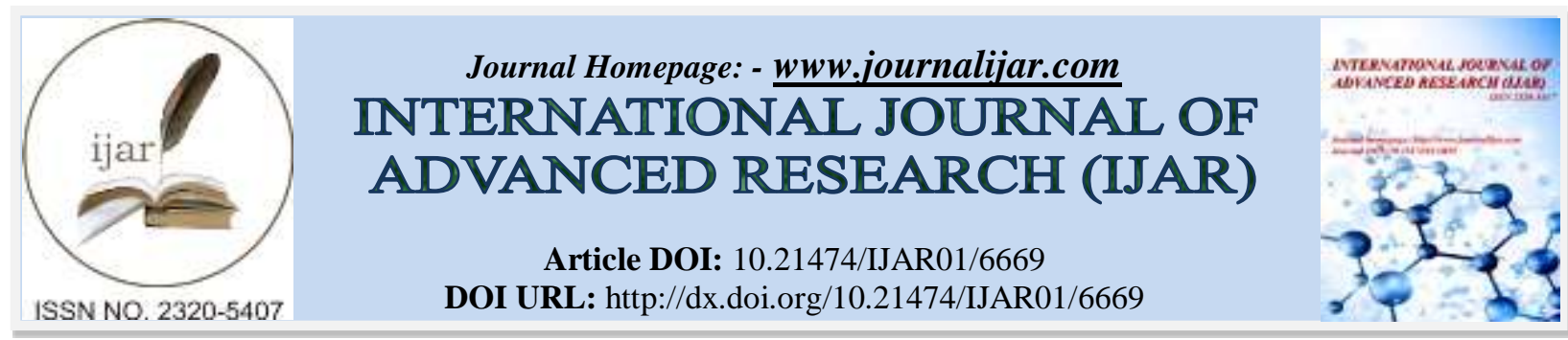

RESEARCH ARTICLE

\title{
A DOSE FINDING STUDY TO EVALUATE THE DURATION OF POSTOPERATIVE ANALGESIA IN UROLOGICAL SURGICAL PATIENTS, USING DIFFERENT DOSES OF EPIDURAL TRAMADOL.
}

\author{
Rasmeet Kour ${ }^{1}$, Qumar- un-Nisa ${ }^{2}$ and Abdul Qayoom Dar ${ }^{3}$. \\ 1. Lecturer, Department of Cardiothoracic Anaesthesia, Super speciality Hospital, GMC, Jammu. \\ 2. Consultant Anaesthesia, Health and Medical Education Deptt. J\&K. \\ 3. Professor, Department of Anaesthesia and Critical care, Sher-i-Kashmir Institute of Medical Sciences, Srinagar.
}

\section{Manuscript Info}

\section{Manuscript History}

Received: 04 January 2018

Final Accepted: 06 February 2018

Published: March 2018

Keywords:-

Epidural, analgesia, Tramadol.

\section{Abstract}

Introduction: Pain control is essential for optimal care of surgical patients. Intravenous drugs need close monitoring and morphine sulphate has serious side effects. Tramadol hydrochloride has been used both intravenously and epidurally and results have been found to be comparable with morphine.

Method: Sixty ASA I and II patients scheduled for elective urological surgery were divided into three equal groups in a randomized, double blinded fashion. Group I, II, III received 1, 2 and $3 \mathrm{mg} / \mathrm{kg}$ body weight epidural Tramadol respectively. Onset time, duration and side effects of analgesia were studied in all the groups.

Result: Duration of pain relief in group I, II, III was 6, 10, $20 \mathrm{hrs}$ respectively which was statistically significant. Incidence of post operative nausea and vomiting was significant in group III compared to other groups.

Conclusion: $2 \mathrm{mg} / \mathrm{kg}$ body weight epidural Tramadol is optimum dose for postoperative analgesia without significant side effects and in dose $3 \mathrm{mg} / \mathrm{kg}$ body weight, can be used with appropriate anti-emetics to reduce the incidence of nausea and vomiting.

Copy Right, IJAR, 2018,. All rights reserved.

\section{Introduction:-}

Pain is one of most distressing symptom of most maladies and adequate and effective pain control is essential for optimal care of surgical patients[1,2].The international association for the study of pain has defined pain as "an unpleasant sensory and emotional experience associated with actual or potential tissue damage, or described in terms of such damage"[3]. The pain in urological surgical patients is moderate to severe degree which cannot be managed by oral or transdermal analgesic drugs. Intramuscular route can be used to inject opioid or non-opioid analgesic drugs, but it is considered painful route and probably not very effective method of pain relief for such a procedure like ureterolithotomy or pyelolithotomy. Intravenous route can effectively be used either by giving a bolus drug or via a patient controlled analgesia (PCA) system. This route needs dedicated staff for close monitoring and a sophisticated PCA system, which most developing nations may not afford [4,5]. Epidural opioids like morphine sulphate and fentanyl in combination with low dose bupivacaine has been used effectively with very good results, but needs a very close observation of these patients in a surgical high dependency unit. Tramadol hydrochloridede has been used both intravenously and epidurally and that results have been found to be comparable with morphine sulphate without serious side effects like sedation or respiratory depression [6-10]. With this background we 
decided to conduct a dose finding study based on body weight, to find out an optimum dose of tramadol hydrochloride to be used epidurally in urological surgical patients.

\section{Material and Methods:-}

This prospective, double blind, randomized study was conducted in the department of Anaesthesiology and Critical Care of a tertiary care hospital during 2006-2008. All the patients with American Society of Anaesthesiologists (ASA) status I and II admitted for urological surgery such as ureterolithotomy, pyelolithotomy, nephrolithotomy and pyeloplasty were eligible to be included in the study. All the patients were informed about the purpose of the study and written consent was obtained from them after seeking approval from the hospital ethics committee to conduct this study.

\section{Randomization:}

The patients in the study were then randomized to receive either $1 \mathrm{mg} / \mathrm{kg}, 2 \mathrm{mg} / \mathrm{kg}$ or $3 \mathrm{mg} / \mathrm{kg}$ of epidural tramadol hydrochloride and were blinded to the person who injected the drug keeping volume of drug same. The procedure was performed with the help of table of random numbers. Sample size:

A minimum of 20 patients in each group was required to study if a statistically significant difference of 3 hours in providing pain relief among three groups as the primary outcome. Such numbers provide us with a confidence of $95 \%(0.05)$ and power of $80 \%$.

At the preoperative visit, patients were instructed in the evaluation of pain using visual analogue scale (VAS) of 0$10 \mathrm{~cm}(0 \mathrm{~cm}=$ no pain, and $10 \mathrm{~cm}=$ the worst pain) [11]. On the evening before operation all patients were clinically evaluated, assured and investigated. The patients were requested to fast overnight. On arrival of the patient in the operating room, an I/V line was established and standard monitoring was established. The patients were kept in sitting position. Under all aseptic precautions and infiltrating the skin around the epidural injection site with lignocaine hydrochloride 2\%. 18 gauge Touhy epidural needle was inserted into the space using a midline lumbar approach at L2-L3 or L1-L2 interspace. The epidural space was identified by the loss of resistance technique. Epidural catheter was inserted and fixed at $4 \mathrm{~cm}$ inside the space. A test dose of $1 \mathrm{mg} / \mathrm{kg}$ of lignocaine hydrochloride without preservative (xylocard) was injected to rule out intravascular or intrathecal placement of the catheter. General anaesthesia was administered after turning the patient to supine position..At the end of the surgery, as per randomization, the epidural Tramadol hydrochloride either $1 \mathrm{mg} / \mathrm{kg}, 2 \mathrm{mg} / \mathrm{kg}$ or $3 \mathrm{mg} / \mathrm{kg}$ was administered in the postanaesthesia care unit (PACU) when patients would complain of pain and VAS was more than 3 . Vital signs were recorded for 30 minutes after injection. When patient experienced pain in postoperative period and request for analgesia was made and VAS was more than 3, then $10 \mathrm{ml}$ of $0.25 \%$ presevative free bupivacaine was administered via epidural catheter as rescue analgesia and time to 1st request for analgesia was noted. If analgesia was not achieved with bupivacaine also, this would be considered a failure of epidural and was excluded from the study. The same was repeated.

\section{Monitoring:}

Patients were monitored half hourly for first 2 hours, hourly for next 4 hours and 2 hourly till patient requested for analgesia postoperatively. Pain was monitored using visual analogue scale. Side effects like nausea, vomiting, dizziness, sweating, and headache were recorded. In patients who needed rescue analgesia with $0.25 \%$ bupivacaine $(10 \mathrm{ml})$ monitoring of heart rate and blood pressure every 15 minute for 1 hour and then hourly for another 6 hours was done.

Statistical analysis:

The observed data was entered in the computer to analyse. With the help of MS, Excel and SPSS version 12.0 for windows. The primary outcome measure was presented as mean and SD and statistically significant difference was evaluated using one way ANOVA. Statistically significant difference of qualitable variables among three groups was evaluated using Chi square / Fishers exact test. A p value of $<0.05$ was considered as significant.

\section{Results:-}

Out of the 20 patients studied in Group I (Tramadol hydrochloride $1 \mathrm{mg}$ per $\mathrm{Kg}$ body weight), pain relief lasted for six hours in 18 patients and 12 hours in 2 patients. In Group II (Tramadol hydrochloride 2 mg per Kg body weight), $18 / 20$ patients had pain relief for 10 hours and only 2/20 patients were pain free for 24 hours. In Group III 
(Tramadol hydrochloride $3 \mathrm{mg}$ per Kg body weight), all the patients were pain free for 20 hours. ANOVA between the groups did not show statistically significant difference for first four hours but the difference was highly significant from fourth hour onwards to 20th hour post injection [Table 1].

Table 1:- Comparison of postoperative analgesia in three study groups

\begin{tabular}{|l|l|l|l|l|l|l|l|}
\hline \multirow{2}{*}{ Analgesia } & \multicolumn{2}{l|}{ Group I } & \multicolumn{2}{l|}{ Group II } & \multicolumn{2}{l|}{ Group III } & \multirow{2}{*}{ value } \\
\cline { 2 - 9 } & $\mathrm{n}$ & $\%$ & $\mathrm{n}$ & $\%$ & $\mathrm{~N}$ & $\%$ & \\
\hline 0 hour & 20 & 100.0 & 20 & 100.0 & 20 & 100.0 & 1.000 \\
\hline 30 minute & 0 & 0.0 & 2 & 10.0 & 0 & 0.0 & 0.367 \\
\hline 60 minute & 1 & 5.0 & 0 & 0.0 & 0 & 0.0 & 0.145 \\
\hline 90 minute & 0 & 0.0 & 0 & 0.0 & 0 & 0.0 & 1.000 \\
\hline 120 minute & 0 & 0.0 & 0 & 0.0 & 0 & 0.0 & 1.000 \\
\hline 3 hours & 0 & 0.0 & 0 & 0.0 & 0 & 0.0 & 1.000 \\
\hline 4 hours & 1 & 5.3 & 0 & 0.0 & 0 & 0.0 & 0.368 \\
\hline 6 hours & 5 & 27.8 & 0 & 0.0 & 0 & 0.0 & $0.003^{*}$ \\
\hline 8 hours & 7 & 53.8 & 0 & 0.0 & 0 & 0.0 & $0.000^{*}$ \\
\hline 10 hours & 4 & 66.7 & 1 & 5.6 & 0 & 0.0 & $0.000^{*}$ \\
\hline 12 hours & 2 & 100.0 & 1 & 6.3 & 1 & 5.0 & $0.000^{*}$ \\
\hline 14 hours & 0 & 0.0 & 3 & 21.4 & 0 & 0.0 & $0.037^{*}$ \\
\hline 16 hours & 0 & 0.0 & 0 & 0.0 & 0 & 0.0 & 1.000 \\
\hline 18 hours & 0 & 0.0 & 7 & 70.0 & 1 & 5.3 & $0.000^{*}$ \\
\hline 20 hours & 0 & 0.0 & 1 & 33.3 & 0 & 0.0 & $0.014^{*}$ \\
\hline 24 hours & 0 & 0.0 & 2 & 100.0 & 6 & 35.3 & 0.088 \\
\hline
\end{tabular}

*significant

Mean time to request analgesia was significantly different between groups. It varied from $6 \pm 2.3$ hours in $1 \mathrm{mg}$ per $\mathrm{Kg}$ Tramadol hydrochloride group to $21.4 \pm 3.7$ hours in $3 \mathrm{mg}$ per $\mathrm{Kg}$ Tramadol hydrochloride group $(\mathrm{p}<.001)$ [Table 2].

Table 2:- Time for first request for analgesia (hr) in 3 study groups

\begin{tabular}{|l|l|l|l|l|}
\hline & Min & Max & Mean & \\
\hline Group I & 0.5 & 10 & $6.0 \pm 2.3$ & $\mathrm{~A}: \mathrm{p}=0.00($ Sig $)$ \\
\hline sGroup II & 0 & 24 & $14.8 \pm 6.7$ & B: $\mathrm{p}=0.00($ Sig$)$ \\
\hline Group III & 10 & 24 & $21.4 \pm 3.7$ & C: $\mathrm{p}=0.00($ Sig $)$ \\
\hline Total & 0 & 24 & $14.1 \pm 7.8$ & $\mathrm{D} ; \mathrm{p}=0.00($ Sig$)$ \\
\hline
\end{tabular}

The only side effect of significance was postoperative nausea and vomiting (PONV). Two patients in Group I and eight patients in group III vomited in first hour after the injection. However, after first hour, eleven patients had PONV in Group III as compared to none in Group I and Group II. Surprisingly only one patient complained of nausea in Group II although the VAS score were comparable between the groups in first hour [Table 3]. None of the patients in our study complained of dizziness, sweating, pruritus or headache.

Table 3:- PONV in patients across three study groups

\begin{tabular}{|l|l|l|l|l|l|l|l|}
\hline \multirow{2}{*}{ Complaints } & \multicolumn{2}{l|}{ Group I } & \multicolumn{2}{l|}{ Group II } & \multicolumn{2}{l|}{ Group III } & \multirow{2}{*}{ v value } \\
\cline { 2 - 8 } & $\mathrm{n}$ & $\%$ & $\mathrm{~N}$ & $\%$ & $\mathrm{n}$ & $\%$ & \\
\hline 0 hour & 1 & 5.6 & 0 & 0.0 & 3 & 15.0 & 0.172 \\
\hline 30 minute & 2 & 10.0 & 0 & 0.0 & 3 & 15.0 & 0.223 \\
\hline 60 minute & 2 & 10.0 & 0 & 0.0 & 1 & 5.0 & 0.387 \\
\hline 90 minute & 0 & 0.0 & 0 & 0.0 & 1 & 5.0 & 0.397 \\
\hline 120 minute & 0 & 0.0 & 0 & 0.0 & 1 & 5.0 & 0.407 \\
\hline 3 hours & 0 & 0.0 & 0 & 0.0 & 2 & 10.0 & 0.160 \\
\hline 4 hours & 0 & 0.0 & 0 & 0.0 & 1 & 5.0 & 0.407 \\
\hline 6 hours & 0 & 0.0 & 0 & 0.0 & 0 & 0.0 & 1.000 \\
\hline 8 hours & 0 & 0.0 & 0 & 0.0 & 0 & 100.0 & 1.000 \\
\hline
\end{tabular}




\begin{tabular}{|l|l|l|l|l|l|l|l|}
\hline 10 hours & 0 & 0.0 & 0 & 0.0 & 2 & 10.0 & 0.308 \\
\hline 12 hours & 0 & 0.0 & 0 & 0.0 & 1 & 5.0 & 0.638 \\
\hline 14 hours & 0 & 0.0 & 0 & 0.0 & 3 & 15.8 & 0.125 \\
\hline 16 hours & 0 & 0.0 & 0 & 0.0 & 0 & 0.0 & 1.000 \\
\hline 18 hours & 0 & 0.0 & 0 & 0.0 & 0 & 0.0 & 1.000 \\
\hline 20 hours & 0 & 0.0 & 1 & 33.3 & 0 & 0.0 & 1.000 \\
\hline 24 hours & 0 & 0.0 & 0 & 0.0 & 0 & 0.0 & 1.000 \\
\hline Total & 2 & 10 & 1 & 5 & 8 & 40 & 0.009 \\
\hline P value & A: 0.533 & & 0.031 & 0.008 & 0.009 \\
\hline
\end{tabular}

\section{Discussion:-}

Significance of pain relief in postoperative period is quite obvious. Satisfactory pain relief beyond doubt keeps up the morale of the patient, facilitates respiratory movements, effective coughing and better oxygenation. It also accelerates mobilization, reduces the risks of deep vein thrombosis, bed sores and muscle wasting [12].Number of workers like Bonica in 1953 [13]; and Bromage in 1967[14] stressed the superiority of epidural analgesia over other techniques for postoperative pain relief. If a method of analgesia is to be successful and available to large number of patients, it must be suitable for use in general surgical ward and require only simple routine nursing monitoring [15]. This dose finding study was undertaken to find the optimum single dose of Tamadol based on body weight to be administered in epidural space to provide pain relief for maximum time period with minimal side effects for urological surgery in adults. Our study shows that in group I $(1 \mathrm{mg} / \mathrm{Kg})$ maximum patients were pain free for 6-8hrs where as in group II $(2 \mathrm{mg} / / \mathrm{Kg})$ the time period was $16-18 \mathrm{hrs}$ and maximum patients were pain free after $24 \mathrm{hrs}$ in group III $(3 \mathrm{mg} / \mathrm{Kg})$. These findings are concordant with other studies which also showed a statistically significant period of pain relief in patients receiving higher dose of Tramadol epidurally [16-19].

The side effects observed in our study are only nausea and vomiting which is consistent with observation made by other workers $[10,20,21]$.

\section{Conclusion:-}

1. $2 \mathrm{mg} / \mathrm{kg}$ body weight is an optimum dose for postoperative analgesia given epidurally without significant increase in side effects.

$2.3 \mathrm{mg} / \mathrm{kg}$ of Tramadol hydrochloride epidurally can be used with appropriate anti-emetics to reduce the incidence of nausea and vomiting associated with this dose.

\section{References:-}

1. Nagema. Measurement and control of postoperative pain. Ann R Coll Engl 1979;6:419.

2. Bonica. Current status of postoperative pain therapy. P169. In Yokota T, Dubner Reds: Current Experta Medica, Amsterdam 1983.

3. Merskey H, Albe Fessard DG, Bonica. Pain term. A list with definitions and notes on usage. Pain 1979;6:249.

4. Graves D, Foster A, Batenhorst RL, Bennett RL. Patient controlled analgesia. Ann Intern Med 1983;99:360.

5. Graves DA, Arrigo JM, Foster TS, et al. Relationship between plasma morphine concentrations and pharmacological effects. Clin Pharm 1985;4:41.

6. Cousins MJ, Cherry DA and Gourlay GK. Acute and chronic pain:Use of spinal opioids. In Cousins MJ and Bridenbough PO. Neural blockade in Clinical Anaesthesia and Management of Pain 2nd ed. pp 993-996, Philadelphia JB Lippincott 1987.

7. Guinard JP, Mavrocordatos P, Cuttat JF and Carpenter R. Arandomized comparison of intravenous versus lumbar and thoracic epidural fentanyl for analgesia after thoracotomy. Anesthesiology 1992;77:1108.

8. Gustafsson LL, Schild B and Jocobsen K. Adverse effects of extradural and intrathecal opiates: Report of a nation wide survey in Sweden. Br J Anaesth 1982;54:479.

9. Demiraran YU, Kocaman B, Akman RY. A comparison of the postoperative analgesic efficacy of single dose epidural tramadol versus morphine in children. BJA 2005;95:510-513.

10. Baraka A, Jabbour $\mathrm{S}$, Ghabash $\mathrm{M}$ et al. A comparison of epidural tramedol and epidural morphine for postoperative analgesia. Can J Anaesth 1993;40:308-313.

11. Price DD, Bush FM, Long S, Harkwins SW. A comparison of pain measurement characteristics of mechanical visual analogue and simple numerical rating scales. Pain 1994;56:217-226.

12. Narain Harisinghain, M. Venogopal et al. Rectus sheath block for postoperative pain relief. Ind. J Anaesthesia 1984;32(3):225. 
13. Bonica JJ. Managaement of pain. Phaladelphia Lea and Febiger 1953.

14. Bromage PR, Comporesi E, Chestnut D. Epidural narcotics for postoperative analgesia. Anesth Analg 1980;59:473.

15. Nimo WS, et al. Pain relief after surgery. Anaessthesia and Intensive Care 1987;15:68-71.

16. Fu YP, Chan KH, Lee TK et al. Epidural tramadol for postoperative pain relief. Ma Tsui Hsueh Tsa Chi 1991;29(3):648-652.

17. AK Pan, Mukherjee P, Rudre A. Role of tramadol hydrochloride on postoperative pain relief in caesarean section delivery. J Indian Med Assoc 1997;95(4): 105-106.

18. DP Prosser, A Davis, PD Booker et al. Caudal tramadol for postoperative analgesia in paediatric hypospadias surgery. BJA 1997;79:293-296.

19. Naquib M, Saraj M, Ahia M, Samarkandi A, Seet M, Jardani R.Perioperative antinoceptive effects of tramadol for postoperative pain relief. Anaesthesia 1993;48:328-31.

20. Chruborik J. Buzina $M$ et al. Intravenous stramadol for postoperative pain-comparision of intermittent close regimen with or without maintenance infusion. Eur J Anaesthesia 1991;9:23-28.

21. Vikers MD, O'Flaherty D, Szekely SM et al. Tramadol: pain relief by an opioid without depression of respiration. Anaesthesia 1992;47:291-296. 